\title{
Online Educators' Leadership Styles and Sources of Their Support
}

Kerla Minela

Doctor of Education, president of The Association of Online Educaors

\begin{tabular}{l}
\multicolumn{1}{|c}{ ARTICLE INFO } \\
\hline Keywords: \\
Online Educators \\
Leadership Style \\
Professional Support \\
Online Platforms
\end{tabular}

\begin{abstract}
Online education is manifested on three scales: formal, semi-formal and non-formal. The degree of development of each of the scales depends on the socioeconomic, technical, technological development of one country, administrative-legal and political system, its civilization and cultural milieu. It is manifest on platforms and has rules, frameworks, ranges and limitations, which usually is not studied in the formal educational systems, as it is not a part of the curriculum, or is not referred to the system of functioning large and small scales. Thus, as a consequence, educators find themselves in a digital space and become victims with burnout, destroyed knowledge and untapped potential of educational platforms. The subject of this study investigates the relationship between teacher educational background, their leadership styles and support on language teaching platforms. Results showed that educators respond to duty requests, and lead the teaching process in a parallel manner using autocratic, democratic, and liberal leadership styles, and their preferences are not related to educational background. Most of the teachers reported that they have the support from the platform where they teach, educational or other experts' association. In contrast, a small number of participants said they do not receive any support or they have to rely on themselves. The paper discusses the theoretical and practical aspects, in an effort to improve and strengthen program oriented to improvement of online educators' skills and their professional inclusion. Results are useful for policy makers, managers, developers and experts in a field of online education.
\end{abstract}

\section{Introduction}

In education and educational science, there is whole field, that is invented, made or designed with innovation for people and their intention for the purpose of education and its support or development. In the literature, numerous definitions of the terms for that education can be found: web-assisted learning, distance learning, e-learning, online learning, digital education and it is related to education supported by technology. Those terms should be considered in the context of the time and learning paradigm, geographical areas and field from which authors worked. The degree of development of each of online education scales depends on the socioeconomic and technical and technological development of one country, its administrative - legal and political system, and its civilization and cultural milieu, its integration and acceptance in one environment.

In the practice, news day and all around the Globe, we have online learning platforms that are big innovations as a form of learning centers and every institution in dealing with a challenge to make some new ways of education that are interesting for people from all around the world 
and save the original pure nature of those institutions and education itself. Each of these schools has its own rules, frameworks, ranges and limitations, which usually is not studied in most of the formal educational systems as it is not a part of the curriculum and it is not referred to the system of functioning of large and small scales. Thus, as a consequence of it, without guidance and support, educators and students very often find themselves in the digital space and without any training becoming victims of their own burnout, destroyed knowledge and untapped potential of educational platforms. Educators become isolated from their own local community and educational centers and their professional integrations inside their "schools", universities or any other professional center.

In this paper, on the sample of appropriate sample of educators, I investigate the relationship between teachers' educational background, their leadership styles and teacher support. The goal of this study is to better understand the perceptions of teachers in an effort to improve the inclusion process for all educators. This information can help to improve and strengthen program oriented to improvement of online educators' skills and development of online education in general. I explore what do we have online at the present moment and its presentation, and I discuss from many points and by interdisciplinary approach and theories of Mead, Blumer, Goffman, Vygotsky, Taylor those results. The paper discusses the theoretical and practical aspects, as well as results that would be useful for digital policy makers, managers, developers, educators and other experts in a field of online education.

\section{Online Education}

In education and educational science, there is whole field that is invented, made or designed with innovation for people and their intention for the purpose of education and its support or development. In the beginning that was distance education as a very complex phenomena, because having so many interpretations and purposes in many different times, from many different locations, from and for different educators and students. Later on, it is named online or digital education. Online education is education supported by technology. In the literature, numerous definitions of terms can be found: web-assisted learning, distance learning, elearning, online learning.

These terms should be considered in the context of the paradigm of time in which authors worked, as well as level of developmental degrees, geographical areas. True the past distance education was not always digital/online, even due that in the literature is treated as a synonym. This education and its success depend on some factors that effects on it: purpose, paradigm context, type, culture, language, human resources, platform, tools, availability, accessibility, communication, interactivity. All of those factors influence on the quality of this education and its effects. Development of this education in mainly related to redlines and the main scales and sustainability of digital education in the practice.

\subsection{Taylors Theory of Development of Distance Education}

Development of online education and the main scales of sustainability of digital education in the practice are depending on factors that influence of development. The factors of influence were these: the need for a lifelong learning and changes, the establishment of platforms, the development of more sophisticated communications system, technological infrastructures required for online-learning, which were firmly established through improvements in bandwidth, the ubiquity of computers in households, improved technological standards, computers in schools and in workplaces, as well as adaptive nature of technology. (Clarke and Hermens, 2001).

From the very beginnings, distance education can be followed through five different levels or generations. Bearing in mind that every generation hasn't been replaced by the next, but they were collected and persisted in the new versions. The five generations are the following: 
Corresponding education - which is based on press and postal delivery; Multimedia model which combines the press, audio-tapes, video-tapes and CDs; Students were buying materials, then they read it and completed all the activities (with support and feedback) alone. For example, learning of foreign language by listening to video-tapes in combination with the workbook; Tele-learning model - it's the model of synchronous communications using available technologies, such as video-conferences in order to provide educational programs; Flexible learning model - which uses interactive medium by means of internet; this includes the communication through computers; The current fifth generation is so called the Intelligent flexible learning model - main difference between this and fourth generation includes ,access to institutional processes and resources... [which provides] adjustable electronic interface by which students, staff and others can interact with a university (Taylor, 2001, p.10).

This education is based on traditional education and got lots of variations and creative appearance. Development would go from traditional to total and independent online education, where all elements would be supported by online tools. It would not be developed in every geographical area in the same way at the same time, with the same product. (Kerla, 2016). The main scales and sustainability of digital education in the practice would depend on physiological readiness, technical-technological development of teachers/students/society, administrative-legal and political condition, civilization-cultural milieu and language. (Kerla, 2019).

\subsection{Online Platforms are New Learning Centers}

In one of the UONEDU ${ }^{1}$ research, we identify that online education has three dimensions for formal, semiformal and non-formal education on many different platforms for different purposes and roles. Each of these schools has its own rules of organization, frames, domains, and limitations. Those schools are bringing a new paradigm of learning and sharing knowledge, as well as interactions and social, psychological development of participants. Also, there are factors that influence on development of platforms and sustainability of digital education in the practice: physiological readiness, technical-technological development of teachers/students/society, civilization-cultural milieu, administrative-legal and political condition, language. Those factors also effect on communication between educators and other participants of this education on platforms and out of it. Their communication depends on the preference of channels, leading style, role on the platform and experience level and integration level in one society. (Kerla et al. 2019A).

In the practice, news day and all around the Globe, we have online learning platforms that are big innovations as a form of new schools. Those online platforms/schools are giving formal education, by following the national curriculum, as an or-or option (campus or online) and it's recognized by the institution as the same program; and non-formal education by offering "modes of education across the life span, from childhood to old age" (La Belle, 1982).

Platform (Fr. plateforme, 'ground plan', literally 'flat shape') is the surfaces and bases on which two parts connect. In the context of online platforms, people meet and unite in one place to create knowledge and deliver services. Expansion of platforms is influenced by different purposes: trade, market, political purposes, social purposes, and educational purposes. Clarke and Hermens (2001) emphasis factors of influence on platforms development: the need for a lifelong learning and changes, the establishment of platforms, the development of more sophisticated communications system, technological infrastructures required for online-learning, which were firmly established through improvements in

\footnotetext{
${ }^{1}$ The Association of Online Educators
} 
bandwidth, ubiquity of computers in households, improved technological standards, computers in schools and in workplaces, as well as adaptive nature of technology.

Online teaching platforms are a necessary component of teaching and learning on the Internet (Zhuzhu, Wang, and Zhang Weiyuan, 2005). The platform provides materials and content, offers links to other materials and content, exchange opinions, establishes collaborations, defines new roles and new professions. From 2010 begins to develop a vision of contemporary online education through online platforms and "virtual learning environment". Hill (2012) defines online learning platforms as a generic, surface-based term that underpins other interactive content, while platform learning is an integrated set of interactive online services provided by teachers, students, parents and others involved in education and educational support or seeking to enhance "delivery" or management.

The online learning platform are having its own way or organizing and functioning. All representative platforms are having information on its website such as: name, address of the platform's headquarters, privacy policies, rules and regulations for the use of information from the platform (e.g., a student may use information from the platform in accordance with its applicable legal provisions the country where he lives, as well as being able to use and distribute the certificates, which he obtains on the platform). The use of any information on the platform should comply with the website's privacy policies. For the duration of the platform membership, users agree to accept these terms and conditions of use. The rules of conduct of students are defined and representatively published on the pages of the platform with the rules of use and requirements and expectations. Any violation of the prescribed rules of conduct has defined disciplinary procedures in place (e.g. reprimands, counseling, removal of profiles from the platform). The first step to access the platforms is to registration. Registration includes personal information, password, e-mail address; language, country of residence; local currency (if closed platforms), time zone. The registration confirms that the applicant is over age of 16 that he/she accepts the conditions of use of the online platform. In the case of minors, the consent and approval of a guardian or parent is required. In order to use the platform, certain conditions of use are often set, such as having a Skype address, previous experience gained through ITC points, rules of conduct on the platform, etc.

The platforms seek to prevent certain behaviors and secure students and other users from: 1) violence and threats. Security is a priority on platforms. They seek to prevent behaviors that offend others or experience them as psychological harassment, harm or physical pain, or could result in financial harm to others, including theft and vandalism; 2) self-harm. This problem is taken very seriously on the platforms, given that the student is in a comfortable place alone and often without the presence of others, therefore, in relation to the potential problems of the platform, they seek to work with agencies around the world with which they interact to prevent possible abuse or self-harm, such as disorder, suicide, murder, etc. 3 . bullying and harassment. Any form of violence or harassment (eg sending inappropriate messages, unsolicited friend requests, harassing material ...) is sought to be reported. The objectives of the platforms are to provide conditions in which to speak freely about matters and people of public interest, but also to take all measures against violent behavior; 4) hate speech. Platforms do not allow hate speech, attacks on individuals or groups based on their race, ethnicity, national origin, religion, gender, gender, sexual orientation, disability, or health status; 5. nudity and pornography. Platforms have strict rules when it comes to sharing the distribution of pornographic content or any explicit sexual content, because it is a learning platform in which the minor is often involved, but also because of the cultural values and beliefs of the people, by which they may be impaired and offended. convictions. Also, students try to limit nudity on the profile screen, while it is forbidden for teachers; 6 . inappropriate discussions on political or religious topics. The platforms do not allow any discussion on topics that offend other beliefs or contain graphics; 7. violations of the right to 
identity and privacy of students through their voluntary consent to provide personal information, preferences and the choice of methods of communication, as well as their voluntary consent in the recording and distribution of materials in which they are mentioned; 8. infringement of intellectual property rights in platforms, copyright, trademark and other legal rights. They are also required to seek permission before sharing content with platforms; 9. identity and spam theft. Students are asked to comply all members, and not contact them for commercial purposes without their consent. In addition, students are asked not to provide posts or comments, which are for commercial purposes, as this diminishes and adds nothing to the value of the community; 10. fraud and deception. Platforms take climate management very seriously on platforms and the way members present themselves. manage public relations as well as prevent privacy or security threats, including fraud or deception. In addition, students and staff are required to respect all members of the community and not contact them for commercial purposes without their consent (Italki.com).

\subsection{Educators on Online Learning Platforms}

1.3.1. Human Resource Management Tasks

One of the first task and challenge for this creative industry human resource managers is to understand the real situations, and not too burdened with normative theory, and is value neutral in its original form. I will use two theories to understand this step: symbolic interactionism theory and collaborative learning theory. Prominent representatives of symbolic interactionism theory are George Herbert Mead (1863 - 1931), Herbert Blumer (1900 - 1987), Ervin Goffman (1922 - 1982). George Herbert Mead believes that interaction does not take place according to the principle of reaction to stimulations, but that interaction occurs via symbols (gesture, language). In illuminating this thesis, he introduces the distinction between $M e, I$, and Self: me (social self) as determined by the role that is assigned to an individual within a group: role in the game, role of the scientist, etc.; And (I as the subject) is the individual's reaction to Me; Self (identity) stems from the relationship between $\mathrm{Me}$ and I. Herbert Blumer, Mead's student, introduced the concept of symbolic interactionism. He was more concerned with the formulation of Mead's basic principles. For Erwin Goffman, human action is characterized by taking on specific roles, whereby the individual in each case is personally content, by showing himself preoccupied with the role, or by making it clear that he is distancing himself from the role (König and Zedler, 2001).

Their theory basic principles were laid down by Herbert Blumer and later supplemented by other representatives:" 1 . Humans do not respond to stimulants, but act on the meanings they attach to a particular situation; 2. Subjects, persons and situations have the same meaning as defined by the rules for all persons belonging to a particular group; 3. In addition, objects, persons and situations have a "subjective meaning" for each individual, whereby the person concerned interprets the general rules of conduct". Other authors (listed above) who support these principles also cite the principle: "4. Uncertainty about the meaning of a situation leads to a loss of orientation in practical action; 5. Human action has meaning, it cannot be explained by descriptiveness of the given and given, because it is necessarily, in action, subjectively colored" (Konig and Zedler, 2003, pp. 152-163).

Theory by Vygotsky about collaborative learning (1978) also teaches us about the fundamental role of social interaction in the development of cognition, that can be applied to the development of online educators. The community plays a central role in the process of "making meaning" through social interaction with a knowledgeable other. Learning is a necessary and ,a universal aspect of the process of developing culturally organized, specifically human psychological function". The main principles of Vygotsky's work are: The More Knowledgeable Other (MKO) and the Zone of Proximal Development (ZPD). The More Knowledgeable Other is somewhat self-explanatory; it refers to someone, it could be a 
teacher or an older adult that has better understanding or a higher ability level than the learner for a particular task, process, or concept. New days are using online educators or some programs with more knowledge about the topic. The Zone of Proximal Development as the area where the most sensitive instruction or guidance should be given - allowing the child/adult to develop skills they will then use on their own - developing higher mental functions.

Human resources, that is, their knowledge and skills, represent the most important resource in an organization, which is essentially the root for the construction and long-term preservation of competitive advantages (Rahimić, 2010). Human resources have become the most important factor in the business and development of organizations due to the large-scale and comprehensive changes in the business environment, and in one society and in general. To consider educators through the prism of resources on online platforms, it can be identified that the key resources of online platforms are platform educators, their knowledge and capabilities. Ones as they select and recruit human recourses from many different countries, online learning platforms must educate and encourage educators to continue their development in/about certain cultural settings. Benat, Ribić, \& Quien (2017) suggest that supporting and educating teachers on implementation of new educational strategies that incorporate digital technology might be a key to achieving student's potential in adopting and applying new knowledge, and that responding to these challenges were the main driver in creating the concept of e-Schools learning scenarios.

Requirements for HRM activities have changed in online settings. Most of the platforms are having poor or not having HRM at all, and teachers are relaying on their own recourses, and connections. The challenges of building environment are on the shoulders of educators and "the dilemma of too much or too little social interaction online, feelings of isolation, the connectedness of teachers and students in building a community of learners" (Bibeau, 2001). Changes in a way of organizing learning centers have also brought new occupations, roles and activities of "(self)employees" and in that sense recruiting and developing teachers.

\subsubsection{Online Educators and Their Competences}

In online classes, as well as in traditional teaching, which takes place in the classroom, teachers primarily seen as a mediator between the content and the participants. In both cases, the aim is to successfully transfer knowledge and skills in specific fields to the trainees. However, the teaching methods and methods may not be the same with regard to the conditions in which they take place.

Pivač \& Kerla (2014) addressed that online language educators are divided into "professional teachers" and "community tutors" with regard to their qualifications and previous experience. Professional teachers or those who have studied a foreign language and who have the following qualifications: the certificate that they can teach at school or university, University Degree in Education, Teaching certificate (like TOESL or TESOL). Professional teachers offer structured classes, the classes should be previously prepared with all the necessary teaching materials. They can teach all aspects of foreign languages, including oral communication, grammar, pronunciation, writing and more. If you are a beginner in learning a language, this type of teacher would be the appropriate because you can get a structured learning plan and pass step by step through the learning process. Community tutors are native speakers (or almost native speakers) that can help you learn a language through informal tutoring or conversation. They do not have qualifications and they are not learning a language for life, neither having a degree in education. However, most of them are familiar with it and have a strong desire to help others in learning a foreign language. Community tutors offer informal tutoring and conversation. From community tutor is not expected to have preparation of the lesson or the syllabus. However, this type of teacher could be your guide, 
respond to your questions or correct some essays. It is up to students, how they will manage with this type of teacher.

Online educators, mostly give technology-assisted teaching. They usually perform their work according to the cybernetic-pedagogical model, which is defined by the representatives of Frank (1960) through four dimensions of didactic decision-making, which represent the conditions on which that decision depends: a) dimensions of didactic decision making that include: the aims of teaching, the intentions that should be pursued by teaching, teaching content, substrates, forms of organization and realization of teaching - and this is precisely the field of methodology, teaching media - as personal as technological; b) dimensions of teaching conditions: anthropological conditions, that is, traits of the students and sociocultural conditions, or characteristics of a narrower and wider social environment.

Mudrinić-Ribić (2005) bring that the competencies of online teachers are conditioned by knowledge and experience in many fields. It assists students in selecting, collecting and organizing content and materials, directs and evaluates them as they learn, and encourages them to achieve the best results. Obviously, such a person must have pedagogical, communication and organizational skills and high professional competence

Caplan (2005) states that the success of online courses requires that teaching staff develop new teaching skills and that their students acquire new administrative and technical skills, namely: a) Pedagogical skills: think of the online environment as just another type of classroom for interacting with students; invest the necessary effort and time to take courses on the Internet; use technology to answer students' queries as well as timely feedback on assignments and grades; to plan creatively the use of technology for effective teaching; $b$ ) Administrative skills: Online teaching often requires more investment in preparation than classroom teaching. Immediately determine the basic rules (plan and program, which should include class rules, e.g. when and in what terms communications can be established) and adhere to those rules; find out where you can find help and use it, such as a help desk for computer help or media development departments. c) Technical skills: basic computer skills; for example, know the basics of document structure, open them, copy them, save and move them, create and manage backup documents, use the mouse and keyboard, screen and windows, and web browsers; understand the basics of Internet functioning, bandwidth and connection speed; d) Time and resources management skills - the teacher mainly spends his / her time answering student emails, grading assignments, and engaging in other interactive teaching components, such as discussion forums and chats.

\subsubsection{Leadership Styles of Online Teaching Process}

Online educators are also leaders of their teaching and learning process. There are numerus papers about leadership style and its influence on learning culture and clime in traditional settings (Amzat \& Yusuf 2019, Uleanya et al., 2019, Farahnak et al. 2019, Mughal, 2019) but not many researches in online settings. Solomon (2019), find positive a relationship between leadership style and school culture of private secondary schools. Democratic, autocratic and laissez-faire leaderships were good predictors of school culture and has significant correlation: autocratic leadership style with collaborative leadership, collegial support and professional development; democratic leadership style had moderate correlation with learning partnership, collaborative leadership, professional development, collegial support, teacher collaboration, and unity of purpose school culture dimensions; laissez-faire leadership style relationship had a weak relationship with learning partnership, also it had a moderate relationship with professional development, unity of purpose, collegial support dimensions of school culture furthermore, it had a strong relationship with collaborative leadership, and teacher collaboration. 
In one of my research in online setting from 2015 about the relationship between leadership styles of teaching process and educational environment have shown that leadership styles of teaching process on platforms are depending of teachers' preference, their occupations and roles, which there take on the platform (certified teachers, online instructors, coaches online teachers assistants), and there were not recorded significant statistical differences in gender variable.

Stripling (2019) had studied the connections between emotional intelligence and leadership styles of school principals of 75 schools in central Alabama and find that certain leadership style is in connection with self-awareness and self-management. The surveys gauged that participants scored higher on the emotional intelligence characteristic of self-awareness and the highest scores on the leadership style of democracy. Also, participant scored the lowest on the emotional intelligence characteristic of self-management and the leadership style of authoritarian.

\subsection{Hypotheses}

The following hypotheses were set:

H1: Educators use different styles of leading teaching process

$\mathrm{H} 2$ : Teachers' educational level has a significant influence on preference of a certain style of leadership

H3: Various sources of support are available to teachers.

\section{Methodology}

\subsection{Subject}

The subject of this study investigates the relationship between teacher educational background, their leadership styles and teacher support. The goal of this study is to better understand the perceptions of teachers in an effort to improve the inclusion process for all educators.

\subsection{Sample}

Convenience sampling of teachers from the former Yugoslavia countries online language teachers that teach at many different teaching platforms Worldwide uses Survey Monkey method. Simple random sampling technique and keywords: online teachers, language teachers, teach online would be used to select respondents for the study and to identify communication channels and identify private and public groups on Facebook platform.

Table 1

Structure of the sample by educational level

\begin{tabular}{ccc}
\hline Educational level & f & \% \\
\hline High school & 14 & 13.6 \\
Bachelor's degree & 39 & 37.9 \\
Master 's degree & 36 & 35.0 \\
PhD & 14 & 13.6 \\
Total & 103 & 100 \\
\hline
\end{tabular}

As shown in Table 1, most of our participants completed their Bachelor studies $(N=39$, i.e. $37.9 \%$ of the whole sample) whereas thirty-six participants (35\%) reported they have 
Master's degree. The number of participants who finished high school and of those who earned their $\mathrm{PhD}$ were equal $(\mathrm{N}=14$, or $13.6 \%$ each).

\subsection{Instrument}

Leadership Styles Questionnaire (LSQ, Northouse, 2011) is comprised of the three following scales: Autocratic leadership (items 1, 4, 7, 10, 13 and 16), Democratic leadership (2, 5, 8, 11, 14 and 17), and Liberal leadership (items 3, 6, 9, 12, 15, 18). Each item was accompanied by a 5-point Likert scale (ranging from 1 to 5) and higher scores mean greater level of a particular leadership style. The scale is moderate for the purpose of this study in terms of self-reporting of leadership styles of teaching process.

Internal consistency of LSQ was checked in this study. Regarding Autocratic leadership, Cronbach's alpha was $a=.624$. However, when the first item was removed (because its corrected item-total correlation was $\left.r_{i t}=.082\right)$, this coefficient increased $(a=.670)$. The first item was: "Students need to be supervised closely, or they are not likely to do their work". As for Democratic leadership, Cronbach's alpha was $a=.793$ and all its items had appropriate values of corrected item-total correlation. The internal consistency of the third LSQ scale was $\mathrm{a}=.631$. We removed its last item, that is, item no. 18 because of corrected item-total correlation of $r_{i t}=.190$. The item no. 18 was: "In general, it is best to leave students alone". As a result, this coefficient was improved $(a=.659)$.

Therefore, all LSQ scales had sufficient level of internal consistency, as one of the scale reliability indicators. Additionally, original version of LSQ was shortened because two items were discarded. In other words, this instrument for the purposes of our study, instead of 18 , included 16 items.

\subsection{Methods}

Content analysis is applied in all social sciences, most notably in history, literature, ethnology, anthropology, sociology, and social psychology. The technique is applied in other types of research (Andrilović, 1988). This method is used in theoretical part of the research. In my research there are analyzed papers, and other social channels that are available for digital educational terms that manifest these scales. Survey method is used to identified leadership style of leading the learning process and channels for support and education.

\subsection{Data and methods}

For analysis it is going to be used qualitative and quantitative approaches, methods and techniques. Statistical analysis is carried out through quantitative methods in SPSS and used the following method: Pearson product- moment correlation coefficient (r) form to calculate the correlation of two variables. It indicates whether the two sets overlap or coincide, the intensity of the match and whether this relationship is directly or inversely proportional. Also, it indicates whether one agrees with the second occurrence of 0 to +1 , and the level of inverse proportionality from 0 to -1 . Inverse proportionally indicates that the presence or extent of one variable negatively affects the extent of the other (Suzić, 2010). Results would be represented by tables. As for descriptive statistical values, means (M), standard deviations (SD), as well as maximum and minimum values were calculated.

\section{Results}

In this section, firstly, I address and explain descriptive statistical values of the three LSQ scales. Then, the results of correlation analysis will be explained. Lastly, the sources of support to online teaching will be listed and discussed.

Participants' scores in each of the LSQ scales were calculated by summing up their scores on each item and dividing the obtained result by the number of items in that scale. Referring to the figures in Table 2, it seems that participants tend to prefer liberal leadership $(M=3.01)$ 
over the autocratic one $(\mathrm{M}=2.93)$. However, the least preferred leadership style is the democratic one $(\mathrm{M}=2.68)$.

Table 2

Descriptive statistical values

\begin{tabular}{llllll}
\hline Scale & N & M & SD & Min & Max \\
\hline Autocratic leadership & 103 & 2.93 & 0.84 & 1 & 5 \\
Democratic leadership & 103 & 2.68 & 0.96 & 1 & 5 \\
Liberal leadership & 103 & 3.01 & 0.80 & 1 & 5 \\
\hline
\end{tabular}

Interestingly, all the leadership styles were in positive, moderate, and statistically significant relationships to each other (Table 3): $r=.491$ (autocratic and democratic), $r=.582$ (autocratic and liberal), and $r=.599$ (democratic and liberal). This means that online educators use autocratic, democratic, and liberal leadership styles in a parallel manner. When most of them use liberal leadership style more, they also increase the use of autocratic and democratic leadership style.

Table 3

The relationships of educational levels with leadership styles

\begin{tabular}{lccc}
\hline Subscales & Democratic leadership & Liberal leadership & Educational level \\
\hline Autocratic leadership & $.491 *$ & $.582^{*}$ & .090 \\
Democratic leadership & & $.599^{*}$ & .036 \\
Liberal leadership & & & .083 \\
\hline
\end{tabular}

Note: $* p<.001$

On the other hand (Table 3), none of those leadership styles was not in a statistically significant correlation with participants' educational level. Correlation coefficient ranged from .036 (educational level and democratic leadership) to .090 (educational level and autocratic leadership). Therefore, educational level is not associated with any of the leadership styles and we have not confirmed our $\mathrm{H} 2$ that teachers' educational level has a significant influence on preference of certain style of leadership.

Table 4

Participants' answers to the question "To teach online, I am supported by..."

\begin{tabular}{ll}
\hline Sources of support & Frequency (f) \\
\hline Supporting team of the platform where I teach & 56 \\
Educational or other experts' association & 35 \\
Educational institution of my country & 28 \\
Non-formal group of teachers or colleagues & 19 \\
Friends and family members & 9 \\
Nobody/nothing & 2 \\
Myself & 1 \\
\hline
\end{tabular}


As shown in Table 4, the most frequent source of support was from the team of the platform where our participants teach (59 of them chose this answer). Secondly, 35 participants reported that they receive support from educational or other experts' association. In contrast, a small number of participants said they do not receive any support or they have to rely on themselves. Based on the this we can confirm H3 that teachers are having different sources of support.

\section{Discussion}

Based on the theory by Mead, Blumer, Ervin, and Goffman (König and Zedler, 2001) interaction does not take place according to the principle of reaction to stimulations, but that interaction occurs via symbolical interaction between me (social self) as determined by the role that is assigned to an individual within a group, And (I as the subject) is the individual's reaction to Me; Self (identity) stems from the relationship between Me and I, in our research it is confirmed the theoretical concept that teachers would lead teaching process on platform based on symbolical principle that: humans do not respond to stimulants but act on the meanings they attach to a particular situation; subjects, persons and situations have the same meaning as defined by the rules for all persons belonging to a particular group; In addition, objects, persons and situations have a "subjective meaning" for each individual, whereby the person concerned interprets the general rules of conduct. Echoing previous studies that have made in campus and online settings (Amzat \& Yusuf 2019, Uleanya et al., 2019, Farahnak et al. 2019, Mughal, 2019, Solomon, 2019), we also identified three leadership style, and identified that participants tend to prefer liberal leadership $(\mathrm{M}=3.01)$ over the autocratic one $(\mathrm{M}=2.93)$ and the least preferred leadership style is the democratic one $(\mathrm{M}=2.68)$. This can be explained as follows: educators, no matter whether they going to be on campus or online settings would respond to stimulants or duty requests, and would lead the teaching process. Furthermore, online educators would prefer liberal leadership style, but they also use autocratic and democratic leadership style, since this way of teaching is semi-formal or informal education and has a different way of organizing, leading and evaluating, which is also confirmed in a study in an online setting conducted by Kerla (2015). The mentioned study was conducted in a different sample shown that leadership styles of teaching process on platforms are depending on teachers' preference, their occupations and roles, which there take on the platform (certified teachers, online instructors, coaches online teachers assistants). In this research, educational level was not associated with any of the leadership styles, and there were not differences in preferences regarding to this variable, that indicate that some other variable has an influence on preferences.

Our results, interestingly shown that, all the leadership styles are in positive, moderate, and statistically significant relationships to each other (Table 3): $r=.491$ (autocratic and democratic), $r=.582$ (autocratic and liberal), and $r=.599$ (democratic and liberal), which means that online educators use autocratic, democratic, and liberal leadership styles in a parallel manner. This can be explained by the theoretical principles of symbolic interaction theory, that subjects, persons and situations have the same meaning as defined by the rules for all persons belonging to a particular group, which means that educators would not have a lot of choices and would use situational rule to respond on stimulants defined by rules of particular group, and requests of students from different cultural background and different leadership preferences and requests for it.

Teachers' perceptions of the support that perceived in our research is the most frequent source of support of the team on the platform where our participants teach (59 of them chose this answer). Secondly, 35 participants reported that they receive support from educational or other experts' association. In contrast, a small number of participants said they do not receive any support or they have to rely on themselves. This can be explained by the fact those 
teachers who interact with team form the platform or and other educational and associational institution would feel supported and perceived those interactions. As it was foreseen, the greater confirmation of the Vygotsky collaborative learning theory of social interaction to the development of cognition, that can be applied on development of online educators and that community plays a central role in the process of "making meaning" through social interaction with a knowledgeable other. Also, in the same line would be Goffman explanation that human action is characterized by taking on specific roles, whereby the individual in each case is personally content, by showing himself preoccupied with the role, or by making it clear that he is distancing himself from the role. This also indicates uncertainty and not a clear definition of the role of online educators on the platform and not clear interaction with HR managers and consideration of the meaning of a situation that leads to a loss of orientation in practical action.

\section{Conclusion}

Based on our research, it can be concluded that educators in online settings would respond to stimulants or duty requests, and would lead the teaching process in a parallel manner using autocratic, democratic, and liberal leadership styles. They would prefer liberal leadership style, but they also increase the use of autocratic and democratic leadership style and that are not associated with the educational background level. Most of the teachers reported that they have the support from the platform where they teach, educational or other experts' association. In contrast, a small number of participants said they do not receive any support or they have to rely on themselves. This can be explained by the fact those teachers who interact with team form the platform or and other educational and associational institution would feel supported and perceived those interactions.

This can be explained by the theoretical principal of symbolic interaction theory and collaboration theory, that subjects, persons and situations have the same meaning as defined by the rules for all persons belonging to a particular group, which means that educators would not have a lot of choices and would use a situational rule to respond to stimulants defined by rules of particular group, and requests of students from different cultural background and different leadership preferences and requests for it.

In addition to confirming the results of previous research, a contribution offered by the present study is it's uniquely detailed and sophisticated measurement approach, in order to understand the concept of leadership style of online teachers and factors that influence their professional inclusion. Furthermore, as an implication for future research directions, is to explore the relation of leadership style of the students, and identified this holistic effect of parallel use of leadership style in a sense of the cultural background of educators and students, age of students and language they teach; identified what leadership style is in relation with "isolation" and the poorest support on the platform.

Appropriate samples of respondents represent a limitation of this study, and moreover, the size of the sample and the possible results generalize regarding a bigger population size could not be made. Moreover, it is necessary to underline that the correlation studies are not investigating the causes and effects, but they prevent the conclusion regarding cause-effect relationships concerning mentioned research variables.

In addition, as an implication of this research, we present that, keeping in mind that the results of numerous studies imply the effects of self-esteem and the perception of personal competence, as well as the perception of student's school success. By undertaking this research, we tried to relate teachers' perceptions of their own leadership style with certain key constructs - teacher support, and the findings have direct implications for curricular and extracurricular activities for online educators on platforms, in educational institutions and associations, which, through targeting certain activity have the potential to reduce the 
negative effects of perception of isolation and appropriate professional inclusion in residential environment.

\section{Acknowledgment}

This paper is an output of the science project "Online educators and Their Better Inclusion" by The Association of Online Educators. Project time: 30 of May 2019 to 30 of May 2020. Focus Groups: Online Educators. The project manager is Minela Kerla, PhD and team members are UONEDU members. Paper is published with approval of the main board of The Association of Online Educators.

\section{References}

Amzat, I. H., \& Yusuf, H. A. (2019). Leadership Style and School Culture as Perceived by Teachers in Malaysian Northern State Schools. In Predictive Models for School Leadership and Practices (pp. 167-192). IGI Global.

Andrilović, V. (1988). Research Methods and Techniques in the Psychology of Education. Zagreb: Školska knjiga.

Benat, G., Ribić, A. M., \& Quien, M. (2017, January). When Providing ICT in Schools Is not All that It Takes: e-Schools Learning Scenarios as a Support to Innovative Teaching with ICT. In OEB 2017: The global cross-sector conference on technology supported learning and training.

Bibeau, S. (2001). Social presence, isolation, and connectedness in online teaching and learning: From the literature to real life. Journal of Instruction Delivery Systems, 15(3), 35-39.

Farahnak, L. R., Ehrhart, M. G., Torres, E. M., \& Aarons, G. A. (2019). The influence of transformational leadership and leader attitudes on subordinate attitudes and implementation success. Journal of Leadership \& Organizational Studies, 1548051818824529.

Frank, H.G. (1969), Kybernetische Grundlagen der Pädagogik, sv. 1,2, Agis, Baden-Baden.

Hill, P. (2012). What is a Learning Platform? [Online]. Available: http://mfeldstein. com/what-is-a-learning-platform/

Isman, A., \& Dabaj, F. (2004). Roles of the students and teachers in distance education. In Society for Information Technology \& Teacher Education International Conference (pp. 497-502). Association for the Advancement of Computing in Education (AACE).

Italki (2019). Community Guidelines. [Online]. Available: http://support.italki.com/entries/ 21680294-italki-Community-Guidelines.

Kerla, M. (2016). Analysis of Learning at Online Platforms Aimed at Improving Nurture and Education process (doctoral dissertation. Sarajevo University.

Kerla, M. (2018). Learning and learning(s) on the Online Learning Platforms. Morrisville, North Carolina: Lulu.

Kerla, M. (2019A). Sustainable Scales of Digital Educations. $2^{\text {nd }}$ Conferences of Online Educators: Online Teaching Challenges in 2019. Sarajevo $1^{\text {st }}$ of February.

Kerla, M. (2019B). Online Learning Platforms as New Schools: UONEDU Case Study. Cost Action WG4: Citizen Science \& Social Innovations, 15-16 April, 2019. Kaunas, Lithuania. 
Kerla, M. (2019C). Presents of Online Tools to Promote Collaboration and Education with Museums. Museum and Democracy in Mediterranean Europe - Art, History and Citizenship XX and XXI centuries at Casa de Velazquez. 3-5 July. Madrid, Spain.

König ,E. I Zedler,P. (2001). Teorije znanosti o odgoju. Zagreb: Educa.

La Belle, T. J. (1982). Formal, nonformal and informal education: A holistic perspective on lifelong learning. International review of education, 28(2), 159-175.

Mudrinić -Ribić, A. (2005). Uloga online nastavnika u e- obrazovanju. Edupoint. Studeni 2005./V/ ISSN 1333-5987.

Mughal, M., Bahaudin, A., \& Salleh, N. (2019). Behavioral factors for IT project success in Pakistan: Moderating effect of leadership styles. Management Science Letters, 9(7), 987996.

Mughal, M., Bahaudin, A., \& Salleh, N. (2019). Behavioral factors for IT project success in Pakistan: Moderating effect of leadership styles. Management Science Letters, 9(7), 987996.

Pivač, M., \& Kerla, M. (2014). Online Teaching in the Context of ITalki-platform and Teaching of French as a Foreign Language. Linguistics, Culture and Identity in ForeignLanguage Education, 1325.

Rahimić, Z. (2010). Menadžment ljudskih resursa. Ekonomski fakultet.

Solomon, H. (2019). The Relationship Between Leadership Style and School Culture in Private Secondary Schools of Bole Sub-City Addis (Doctoral dissertation, Addis Ababa University).

Stripling, J. D. (2019). The Relationship between Emotional Intelligence and Leadership Styles in School Principals (Doctoral dissertation, The University of Alabama at Birmingham).

Uleanya, C., Khumalo, P. N., Momah, E., \& Ndlovu, B. B. (2019). Influence of leadership styles on the success of secondary education in Africa: a case study of Nigeria and South Africa. Journal of Gender, Information and Development in Africa (JGIDA), 8(1), 213238.

Vygotsky, L. S. (1978). Mind in society: The development of higher psychological processes Cambridge, MA: Harvard University Press.

Zhuzhu, W., \& Weiyuan, Z. (2005). Online Teaching Platforms and Websites in China's Universities [J]. China Distance Education, 2(10). 